\title{
ОТ МАТЕРИАЛЬНО-ТЕХНИЧЕСКОГО СНАБЖЕНИЯ К ЛОГИСТИКЕ И ОБРАТНО
}

\author{
(c) 2018 Плоткин Борис Кальманович \\ доктор экономических наук, профессор \\ Ассоциация содействия промышленности Научно - экономический комитет \\ г. Санкт-Петербург \\ E-mail:kafedra-kl@yandex.ru \\ (C) 2018 Сосунова Лильяна Алексеевна \\ доктор экономических наук, профессор \\ Самарский государственный экономический университет \\ 443090, г. Самара, ул. Советской Армии, 141 \\ E-mail:kafedra-kl@yandex.ru
}

В статье рассматриваются вопросы: становления логистики, ее взаимосвязь с материально техническим снабжением, представление и осведомленность о логистике; логистика как цепь поставок; транспортная сущность логистики; система кросс - докинг.

Ключевые слова: логистика, материально-техническое снабжение, рыночная экономика, отраслевая логистика, предметная логистика, транспортные услуги, кросс - докинг.

Российская экономика для своих рыночных преобразований получила логистику в полной теоретической готовности. Становление логистики шло в направлении распространения и адаптации её применительно к российским реалиям.

Теоретический потенциал логистики включал научные достижения, наработанные в предыдущий период - в период централизованной плановой системы материально-технического снабжения [1].

Логистика была введена в научный и практический оборот с началом перехода на рыночные товарно-денежные отношения между предприятиями. Появление логистики было обусловлено тем, что в административно-командной экономике был присущ постоянный дефицит материальных ресурсов для производственных нужд, вследствие чего предприятия испытывали трудности в снабжении. К моменту рыночных преобразований материально-техническое снабжение как вид деятельности и профессия были весьма скомпрометированы: потребовалось другой наименование и того и другого. Так появилась логистика.

Изначально логистика использовалась в военном деле: для ведения военных действий необходимы огромные материальные затраты, предвидеть различные случайности, учитывать множество факторов, выполнять сложные рас- четы - все это требует высокого искусства. Такое искусство именуется греческим словом «ло-

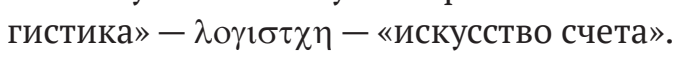

Авторитетные энциклопедические словари (Вебстер, Ларусс) слово «логистика» дают с пометой «воен.» и объясняют как «тыл и снабжение вооруженных сил». Так логистика была распространена на всё снабжение. Соответственно кафедры материально-технического снабжения стали именоваться как кафедры логистики.

Материально-техническое снабжение стало осуществляться с помощью оптовой торговли продукции производственного назначения, вследствие чего логистика, по праву, стала именоваться «коммерческой».

K началу экономических преобразований в полной мере сформировалась научно-теоретическая база материально-технического снабжения, которая в полной мере должна быть использована в логистике. К числу важнейших достижений предшествующего - планового периода следует отнести:

1) была сформирована достаточно развитая теория нормирования расхода материальных ресурсов;

2) разработаны методические основы достоверного определения потребности в материальных ресурсах с помощью метода «прямого счета»;

3) обоснован порядок расчета цен закупки 
и определения сумм материальных затрат;

4) сформирована совокупность критериев для оценки качества поставщиков, что является составной частью алгоритма оптимизации закупок;

5) разработаны методические основы расчета календарных графиков поставок материальных ресурсов на предприятие;

6) обоснована необходимость выполнения услуг при поставках продукции - подготовка материальных ресурсов к производственному потреблению (раскрой, нарезка, сортировка и т.п.);

7) отработана система количественной и качественной приемки поступающей на предприятие продукции;

8) получило признание научное управление запасами.

Следует подчеркнуть, что все достижения научной мысли в основном были только в теории, поскольку плановая система не давала предприятиям необходимой для этого самостоятельности и не стимулировала организацию материально-технического снабжения на оптимальном уровне.

В условиях рыночной экономики большинство научных достижений предшествующего периода с помощью логистики стали использоваться в снабжении производственных предприятий.

Накопленный научный потенциал вывел логистику в число новых экономических наук. Одновременно стало ясным, что полное и адекватное освоение логистики как науки требует от ученых и практиков высокого профессионализма и интеллекта. Иными словами, логистика может развиваться и использоваться на практике только под воздействием человеческого фактора - при наличии высококвалифицированного персонала [2].

Начало для логистики было весьма многообещающим. Те, кто кое-что слышал о логистике и не путал её с логикой, восприняли логистику с большими надеждами на будущее - это были специалисты «снабженческой» школы. Был энтузиазм - энтузиазм обусловлен тем, что благодаря рынку «сбылись мечты» снабженцев, а именно:

1) появилась в полном объеме оптовая торговля средствами производства;

2) был ликвидирован товарный дефицит, в том числе и на продукцию производственного назначения;

3) появилось самостоятельность предприятий - ушел в прошлое диктат «плана» и вышестоящих «руководящих» органов;

4) стало возможным применять методы теории управления запасами;

5) стало возможным оперативное маневрирование материальными ресурсами;

6) стали развиваться услуги и инфраструктура при поставках продукции;

7) существенно сократились документооборот и отчетность;

8) отменена монополия внешней торговли - расширилось рыночное пространство.

Интенсивно стали проводиться научные исследования по логистике. Выявились два направления научных исследований по логистике:

1) отраслевая логистика - например, логистика машиностроения, логистика сельского хозяйства, логистика угольной промышленности, логистика жилищно-коммунального хозяйства и т.П.;

2) предметная логистика - применительно к разным видам товаров и услуг, например, логистика строительных материалов, логистика мясной продукции, логистика фармацевтической продукции и т.п.

Но при этом нередки случаи, когда логистика просто «притягивалась за уши» к той или иной проблеме. Появились такие «логистики»: «логистика отдыха и досуга», «биржевая логистика», «банковская логистика», даже такая экзотическая логистика, как логистика девелопмента и таких примеров - множество.

Снабженческо-сбытовая деятельность получила весьма мощный импульс, но на практике меньше всего это связывалось с логистикой работники использовали накопленные квалификацию и опыт, но без должного интереса к логистике. Как уже отмечалось, исчезли трудности со снабжением, а сбыт скорее связывался с маркетингом и меньше всего с логистикой.

В отличие от логистики маркетинг широко освещался не только в специальной литературе, но в средствах массовой информации. До настоящего времени практические работники - менеджеры и специалисты - имеют лишь приближенное представление о логистике [3].

Для выявления осведомленности о логистике был проведен опрос среди работников производственных и торговых предприятий. Результаты указанного опроса представлены в табл. 1 . 
Таблица 1. Представление и осведомленность о логистике

\begin{tabular}{|c|l|c|}
\hline №№ пп & \multicolumn{1}{|c|}{ Представления о логистике } & \%\% \\
\hline 1 & Транспортные услуги и перемещение продукции & 38 \\
\hline 2 & Транспортная доступность и подъездные пути предприятия & 30 \\
\hline 3 & Формирование и поддержание запасов на необходимом уровне & 12 \\
\hline 4 & Закупки товаров для производственной и торговой деятельности & 8 \\
\hline 5 & Приемка товаров в торговой сети & 6 \\
\hline 6 & Сбыт, продажи, обслуживание покупателей & 4 \\
\hline 7 & Общее руководство фирмой & 2 \\
\hline & Итого & 100 \\
\hline
\end{tabular}

Важно отметить, что опрос проводился в профессиональной среде, а поэтому все ответы в той или иной мере касались логистики. Однако большинство логистику ассоциирует с транспортом (68\%). Примечательно, что к логистике некоторая часть торгово-промышленного персонала относит и запасы, тем самым признается место запасов в логистике.

Такие базисные логистические процессы как «закупки» и «продажи» весьма малая часть опрошенных (12\%) относит к логистике. Такое суждение было обусловлено тем, что среди участников опроса были работники розничных сетей и обслуживающих их распределительных центров.

Некоторые профессионалы-экономисты логистикой считали техническую эксплуатацию транспортных средств, работу с персоналом, проведение выставок и ярмарок для продвижения новых товаров, оценку эффективности работы менеджеров, консультационная деятельность и многое другое. Такое многообразие суждений, как уже отмечалось, обусловлено стремление «притянуть»к логистике всё без разбора. Но в то же время представляется отрадным, что экономисты в своем большинстве перестали смешивать «логистику» с «логикой» - уяснили, что это разные вещи.

Следует признать, что объемная научная информация по логистике носит в основном теоретический характер - на долю практики приходится не более $5 \%$.

Итак, во что трансформировалась логистика и её современное состояние? Из всего изложенного можно сделать следующие выводы:

1. Логистика меньше всего считается альтернативой и синонимом материально-технического снабжения, поскольку товарный дефицит ликвидирован и тем самым исчезли трудности в снабжении. Такое положение вызывает сомнение в необходимости логистики как самостоя- тельного вида деятельности с таким названием для снабженческо-сбытовой деятельности;

2. Почти полностью игнорируется финансовая составляющая материально-технического снабжения, ибо деятельность служб снабжения, как и прежде, направлена на обеспечение производства материальными ресурсами.

Не соблюдается требование, согласно которому материальными ресурсами должно обеспечиваться только конкурентоспособное производство. Как только предприятие становится неспособным получать доход необходимой величины, снабжение должно прекращаться. Нарушение указанного требования является одной из причин долгов предприятия, а то и банкротства.

3. Притом, что трудности возникли с реализацией готовой продукции, персонал службы сбыта процессы продаж не связывают с логистикой - в сбытовой деятельности приоритет отдается маркетингу. Однако на практике получаемая маркетинговая информация ещё не используется надлежащим образом в системе продаж. Бытует мнение, что трудности с продажами обусловлены внешними факторами: общей рыночной ситуацией, макроэкономическими действиями, конкуренцией, платежеспособностью и др. В ограниченном объеме для некоторых видов продукции применяются логистические приемы сбыта с использованием концепций Effective Customer Response (ECR): «Эффективная реакция на запросы потребителей» и Vendor Managed Inventory (VMI): «Управление запасами поставщиком».

4. Ключевое понятие логистики как цепи поставок в реальности представляют собой концзептуальную систему, а поэтому на микроэкономическом уровне, т.е. на практике являются абстракцией.

Предприятия, образующие «цепь поста- 
вок», функционируют независимо друг от друга, ориентируясь на свои собственные интересы, т.е. «цепь» в виде системы не образуется. Концепцию логистики SCM «Управление цепями поставок» следует признать неудачным заимствованием, поскольку таковых в реальности нет. Для западной экономики с её многолетним опытом применение SCM вполне обосновано, поскольку предприятия применяют логистические концепции в полном объеме. В российской экономике цепи поставок в той или иной мере функционируют в строительстве и военно-промышленном комплексе (ВПК) благодаря наличию на предприятиях этого комплекса представителей заказчика.

Следует отметить, что на практике происходит процесс кластеризации - образования кластеров в виде групп предприятия - производственных и торговых. В данном случае просматривается предметная специализация кластеров.

Предприятия каждого кластера функционируют в автономном режиме, руководствуясь своими интересами. Но при этом проявляются и объективно существуют неформальные связи: профессиональные, технологические, консультационные и др. В силу универсальности логистики (в данном случае её «всеядности») появляются рассуждения о «логистизации кластеров» или о «кластерной логистике». Так, в статье Борисенко А.Н. логистика рассматривается как «адекватная система логистики не ограничивается управлением отдельными запасами или транспортными потоками, а представляет собой концепцию исследования и повышения эффективности производственных систем, включающих несколько имущественно-хозяйственных комплексов» [4].

В современной экономике полностью отсутствует логистическая деятельность как реализация на практике научного потенциала, каким обладает теория логистики. Такое положение обусловлено тем, что логистика не получила должного распространения в практическом сообществе экономистов.

В действующей номенклатуре должностей отсутствуют должности с наименованием «логист» или «логистический» - такое же положение наблюдается и в штатных расписаниях производственных предприятий.

Логистика по-прежнему остается экзотикой. В данном аспекте представляет интерес срав- нение с маркетингом. Так, маркетинг как рынковедение или наука о рынке, весьма широко известен и в крупных оптово-торговых центрах имеются престижные должности - «маркетолог», но при этом отсутствуют службы маркетинга на производственных предприятиях.

Парадокс заключается в том, что логистика охватывает всю реальную экономику - все процессы товародвижения в натурально-вещественной и стоимостной формах, а маркетинг имеет дело только с информацией и результатом маркетинговой деятельности также является информация. Возникает вопрос: «Имеются ли в экономике профессионалы по логистике?» Да, имеются, но называются они по-другому и по-разному: от новых «менеджеров» и до традиционных работников по соответствующим направлениям - по закупкам, по продажам, по транспорту.

Современный инструментарий логистики полностью компьютеризирован: все логистические концепции от SCM и до VMI включают программные модули. Компьютерные технологии поглотили логистику. Сформировалась автоматизированная логистическая система управления на качественно новом уровне в русле всеобщей компьютеризации экономики.

В предыдущие периоды вычислительная техника была помощником работника - в настоящее время компьютеры являются партнерами специалистов, при этом функции специалистов - это осмысление результатной информации и принятие управленческих решений.

В целом логистика вернулась к своей доминанте - перемещению и транспортировке. В настоящее время логистика связывается именно с транспортом.

Принципиальное различие между логистикой и транспортной отраслью заключается в том, что логистическая транспортировка осуществляется в неразрывной связи с экономикой и перевозимыми товарами - с процессом товародвижения [5]. Транспортная отрасль в основном это техническая эксплуатация транспорта.

Среди собственно логистических форм организации транспортировки следует отметить унимодальные и мульти(интер)модальные перевозки, терминальные и комбинированные перевозки.

Кроме того, специальными правилами регламентируются условия перевозки и фрахта 
(ФАС, ФОБ, СИФ и др.), формы коносаментов и других перевозочных документов, условия оплаты и многое другое.

Таким образом, подготовка к организации и осуществления перевозок требует затрат высокопрофессионального труда персонала специализированных служб и организаций (фирм). На практике вся такая работа, будучи весьма сложной и ответственной, в той или иной мере связывается с логистикой. Более того, работники, занятые перевозочным процессом, полностью сознают, что их деятельность является логистической.

Частью собственно логистики, т.е. её транспортной сущности, является система кроссдокинг.

Кросс-докинг - Cross-docking в переводе с английского значит «прямая стыковка» - процесс приёмки и отгрузки товаров и грузов напрямую, без размещения в зоне долговременного хранения.

Кросс-докинг является совокупностью логистических операций, благодаря которым отгрузка со склада и доставка товаров максимально точно согласуются по времени. В результате продукция доставляется за минимальный срок, а долгосрочное хранение товара на складе полностью исключается.

Кросс-докинг как логистический процесс выдвигает особые требования в адрес складского провайдера в цепи поставки. Рассматриваемая система доставка продукции может расценена как своеобразная концепция JiT - «Точно в срок».

Примечательно, что многие операции и процессы, будучи по своей сущности логистическими, применяются в хозяйственной деятельности под самыми разными названиями. Система кросс-докинг под названием «прямой вариант» издавна применяется на водном транспорте. В морских и речных портах выполняются погрузочно-разгрузочные работы по прямому варианmу: перегрузка грузов осуществляется непосредственно из трюмов судна в железнодорожные вагоны (вариант «судно-вагон») или из вагонов прямо в трюмы судов (вариант «вагон-судно»).

Следует подчеркнуть, что и в административно-командной экономике весьма интенсивно проводилась работа по совершенствованию транспортных процессов в системе снабжения. Эта работа - с точки зрения современности - была в полной мере логистической, хотя в то время такой термин был совсем неизвестен, т.е. дело не в названии, а в сущности проводимых работ.

Так, в частности, к таким работам следует отнести мероприятия, направленные на сопряжение материально-технического снабжения и транспорта. В рамках таких работ была создана Центральная диспетчерская служба складских комплексов, с помощью которой осуществлялось всестороннее и оперативное обслуживание автотранспорта предприятий-потребителей с помощью централизованной доставка грузов.

В современных условиях следует признать, что выражение «транспортная логистика» является тавтологией, ибо раз сказано «логистика», то речь будет идти о транспортировке.

Произошла трансформация логистики в общеэкономическую прикладную научную и учебную дисциплину.

Накопленная обширная научная информация по логистике должна стать теоретическим фундаментом для подготовки современных специалистов по экономике всех его специальностей.

В настоящее время понятие «логистика» получило вполне отраслевое значение и обозначает преимущественно всё, что связано с транспортом и включает весь комплекс основных и инфраструктурных процессов транспортных систем. Снабжение и сбыт следует именовать своими точными названиями.

Важно знать, что материально-техническое снабжение и сбыт есть форма экономического процесса обращения средств производства, а транспорт - отрасль материального производства.

\section{Библиографический список}

1. Проценко О.Д. Логистика // Большая российская энциклопедия: в 30 т. / председатель науч.-ред. Совета Ю.С. Осипов; отв. ред. С.Л. Кравец. Т. 17. Москва. 2010. С. 734 ISBN978-5-85270-350-7 (т. 17) ISBN5-85270320-6

2. Плоткин Б.К. Введение в коммерцию и коммерческую логистику: Учеб. Пособие. Санкт-Петербург. 1996. $171 \mathrm{c.}$ 
3. Плоткин Б.К., Сосунова Л.А., Корнев В.М. Проблемы компетентности специалистов образовательных услуг// Экономические науки. 2018. № 1. С. 22.

4. Борисенко А.Н. Логистика как концептуальная основа исследования территориально распределенных производственных сетей // Экономические науки. 2006. № 12. С. 22

5. Сосунова Л. А. Логистические индикаторы в потоковых процессах // Экономические науки. 2017. № 2. С. 115.

Поступила в редакцию 25.09.2018 